\title{
Identification of an Immune-related Seven-IncRNA Signature Predicting Prognosis and Tumor-infiltrating Immune Cells in Lung Adenocarcinoma
}

Jinchun Wu

Xiangya Hospital Central South University https://orcid.org/0000-0003-2731-0992

Yanhua Mou

Xiangya Hospital Central South University

Chunfang Zhang

Xiangya Hospital Central South University

Chaojun Duan

Xiangya Hospital Central South University

Bin Li ( $\sim$ bincsuxy@csu.edu.cn )

Xiangya Hospital Central South University https://orcid.org/0000-0001-5453-2385

Primary research

Keywords: lung adenocarcinoma, immune-related IncRNAs, TIICs, prognosis

Posted Date: June 30th, 2020

DOI: https://doi.org/10.21203/rs.3.rs-38155/v1

License: (c) (7) This work is licensed under a Creative Commons Attribution 4.0 International License. Read Full License 


\begin{abstract}
Background: Lung adenocarcinoma (LUAD) is a common cancer. Immunotherapy is one of the major treatments but showing diverse efficacy in LUAD. Long non-coding RNAs (IncRNAs) are emerging as important players in immune regulation in cancer. Herein, we identified and validated a prognostic signature of immune-related IncRNAs in LUAD and explored its correlation with tumor-infiltrating immune cells (TIICs) by bioinformatics analysis.

Methods: Immune-related IncRNAs were acquired using Pearson correlation analysis between IncRNAs from The Cancer Genome Atlas (TCGA) and Gene Expression Omnibus (GEO) databases and immune genes from the ImmPort website and Molecular Signatures Database. The risk signature was constructed in the TCGA group through univariable Cox, lasso and multivariable Cox regression analyses. The prognostic value of the established risk signature was validated in both TCGA and GEO datasets. The interacted TIICs and immune pathways with each single IncRNA and the risk signature were investigated respectively in ImmLnc database, Cibersortx database and gene set enrichment analysis (GSEA) analyses.
\end{abstract}

Results: A seven immune-related IncRNAs prognostic signature was constructed and it stratified LUAD into high and low risk groups. High risk group showed poorer overall survival (OS) in comparison with low risk group via survival analysis. The seven-IncRNAs signature was closely correlated with various TIICs and immune pathways mostly involved in T cell activation, antigen processing and presentation, chemokines and cytokine receptors.

Conclusions: The seven IncRNAs model was identified as a predictable signature for prognosis of LUAD patients probably due to its immunomodulation role. This study might provide a new target for enhancing the efficacy of immunotherapy in this mortal disease.

\title{
1. Background
}

In 2018 globocan report, new lung cancer cases were 2,093,876 and the deaths were 1,761,007, both ranked the first position among all malignancies, indicating lung cancer was still the biggest threaten to people worldwide[1]. Lung cancer is generally classified into two distinct classes: small cell lung cancer and non-small cell lung cancer (NSCLC), and the latter occupies more than $80 \%$ of lung cases. Lung adenocarcinoma (LUAD) is the most common subtype of NSCLC, but it is still a heterogeneous disease with diverse molecular signatures and short of predictable prognostic markers [2]. Recently, the application of immune checkpoint blockade (ICB) has dramatically changed the therapeutic scenario of LAUD and improved its overall survival (OS) [3]. But unsatisfactorily, only a fraction of LUAD patients responds to ICB even in the cases with high programmed death-ligand 1(PD-L1) expression [4]. Multifaceted factors cause this diverse efficacies including mismatch repair deficiency, mutation or neo-antigen load and PD-L1 level, but none of these factors is sufficient to predict the prognosis of LUAD under ICB treatment $[5,6]$.

The purpose of ICB treatment is aimed to remove the inhibition role of cancer cells on TIICs, and thus unleash TIICs activation. So the quantity and intrinsic state of TIICs is one of the core factors determining ICB efficacy. The function state of cytotoxic T lymphocytes (CTLs) in tumors predict cancer immunotherapy response, and the interaction of each gene with CTLs infiltration in tumors influence patient survival[ 7,8$]$. TIICs can even induce hyperprogressive disease (HPD) defined as an accelerated growth of cancer cells during ICB treatment. Immune cells including tumor-associated macrophages (TAMs) [9], CD4 T cells[10], CD8 + T cells[11], effector Regulatory T (eTreg) cells [12] and neutrophil-to-lymphocyte ratio [13] were significantly associated with HPD after ICB treatment, hinting the impacts of TIICs on diversified outcomes of ICB in NSCLC.

Long non-coding RNAs (IncRNAs) are non-protein-coding RNAs length greater than 200 nucleotides, joining in genetic transcription, mRNA stability and protein function regulation[14]. LncRNAs are intense participants in numerous stages of tumor immunity through mediating TIICs functions[15], including T cells[16], monocytes[17], macrophages [18] and granulocytic myeloid-derived suppressor cells (G-MDSCs) [19]. LncRNA NKILA induces tumor immune evasion by promoting apoptosis of CTLs and type 1 helper $T\left(T_{H} 1\right)$ cells[16]. LncRNA Pvt1 mediates the immunosuppression function of G-MDSCs weaken ICB efficiency[19], and accumulating evidences further deepen the understanding of the modulation of IncRNAs on TIICs function in recent reports[16, 20]. Herein, we constructed a seven-IncRNAs prognostic signature from filtered immune-related IncRNAs, and explored the correlation of this signature with TIICs in LUAD by comprehensive bioinformation analysis, with the purpose of providing an alternative predictor for LUAD prognostication and possible targets for ICB sensitization.

\section{Materials And Methods}

\subsection{Acquisition of the immune-related IncRNAs in LUAD}

The format of fragments per kilobase of exon per-million fragments (FPKM) of RNA-seq and clinical data of LUAD were obtained from The Cancer Genome Atlas (TCGA, https:// portal.gdc.cancer.gov). Raw data of gene expression, clinical information and platform files were obtained from online database of Gene Expression Omnibus (GEO) (http://www.ncbi.nlm.nih.gov/geo/) [21]. The TCGA datasets were assumed as the discovery group, and two independent GEO cohorts (GSE31210[22, 23] and GSE50081[24]) were processed as the validation groups. Patients with overall survival less than 30 days were excluded since they might die of other diseases rather than LUAD [25].

Next, the annotation of mRNAs and IncRNAs was according to the ensemble genome browser(http://asia.ensembl.org/index.html). By the Pearson analysis, immune-related IncRNAs were filtrated according to their correlations with immune-related genes which were downloaded from the ImmPort (https://www.immport.org/home) [26] and Molecular Signatures Database[27] (https://www.gsea-msigdb.org/gsea/msigdb/index.jsp, immune response M19817 and immune system process M13664).

\subsection{Construction and validation of the risk model}


Immune-related IncRNAs and clinical information were merged to build the prognostic signature using the data from the patients with complete information. The signature was constructed by univariate and multivariate Cox proportional hazards regression and Lasso regression from the TCGA datasets and validated in two GEO datasets. The risk score was calculated as follows:

Risk score $=\sum_{i=1}^{n} \quad\left(\exp _{\mathrm{i}} \times \mathrm{coe}_{\mathrm{i}}\right)$

Pearson analysis within Gene Expression Profiling Interactive Analysis (GEPIA2) database [28] was used to confirm the correlation between the seven IncRNAs and immune genes originated from the TCGA group. According to the median risk score estimated by the IncRNAs through their coefficients of the signature, the LUAD patients were separated into two groups (high risk group and low risk group). Then the prognostic value between clinical features (including age, gender, T, N, M and stage) and the IncRNAs within the signature were compared by univariable and multivariable Cox analyses. Besides, the correlation analysis between the clinical feature and the seven IncRNAs and signature were implemented via Analysis of Variance (ANOVA). The Kaplan-Meier method was used to draw the survival curves, and the sensitivity and specificity of the model were evaluated by the receiver operating characteristic (ROC) curve analysis.

\subsection{TIICs and immune pathways analyses between two risk groups}

The TIICs and immune pathways involved in each single IncRNA were investigated in the ImmLnc database(http://bio-bigdata.hrbmu.edu.cn/ImmLnc/)[29]. Differences of TIICs and immune pathways between the high and low risk groups were analyzed respectively by Cibersortx database[30] and gene set enrichment analysis (GSEA) analysis (desktop version 4.0.3, immunological signatures: c7.all.v7.1.symbols.gmt) [27].

\subsection{Statistical analysis}

All data and figures were processed with R (version 3.6.1) and perl language. The raw data of gene expression profiles from GEO database were standardized

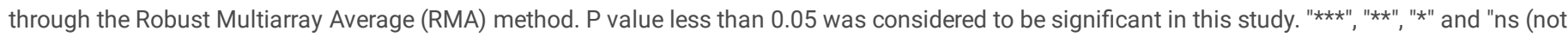
significant)" represent $p<0.001, p<0.01, p<0.05$ and $P>0.05$, respectively.

\section{Results}

\subsection{Patients and immune-related IncRNAs}

After wiping out patients with incomplete clinical information, a total of 486 patients in TCGA datasets, 226 patients in GSE31210 and 127 patients in GSE50081 were included in this study. The TCGA cohort was performed as the training group, and two independent datasets of GSE31210 and GSE50081 were served as the validation groups. The detailed clinical features were summarized in Table 1. A total of 17,351 IncRNAs obtained from TCGA datasets and 1,075 IncRNAs identified from the GEO group were screened and 1,069 common IncRNAs were included in this study. Then through co-expression analysis with 1,986 immune-related genes discerned in TCGA datasets, 206 immune-related IncRNAs were discovered and applied to establish the prognostic risk model. 
Table 1

the clinical characteristics of LUAD from three datasets in this study.

\begin{tabular}{|c|c|c|c|}
\hline Clinical features & Patients of TCGA (\%) & Patients of GSE50081 (\%) & Patients of GSE31210 (\%) \\
\hline \multicolumn{4}{|l|}{ Gender } \\
\hline male & 261(53.7) & $65(51.2)$ & $121(53.5)$ \\
\hline female & $225(46.3)$ & $62(48.8)$ & $105(46.5)$ \\
\hline \multicolumn{4}{|l|}{ Age } \\
\hline$\leq 65$ & $233(47.9)$ & $40(31.5)$ & 176(77.9) \\
\hline$>65$ & $253(52.1)$ & $87(68.5)$ & $50(22.1)$ \\
\hline \multicolumn{4}{|l|}{$\mathrm{T}$} \\
\hline T1 & 163(33.5) & 43(33.8) & 0 \\
\hline T2 & 259(53.3) & $82(64.6)$ & 0 \\
\hline T3 & $43(8.8)$ & $2(1.6)$ & 0 \\
\hline T4 & 18(3.7) & 0 & 0 \\
\hline Tx/unknow & $3(0.6)$ & 0 & $226(100)$ \\
\hline \multicolumn{4}{|l|}{$\mathrm{N}$} \\
\hline NO & $312(64.2)$ & $94(74.0)$ & 0 \\
\hline N1 & $93(19.1)$ & $33(26.0)$ & 0 \\
\hline N2 & $68(14.0)$ & 0 & 0 \\
\hline N3 & $2(0.4)$ & 0 & 0 \\
\hline Nx/unknow & $11(2.3)$ & 0 & $226(100)$ \\
\hline \multicolumn{4}{|l|}{ M } \\
\hline MO & $322(66.3)$ & $127(100)$ & 0 \\
\hline M1 & $24(4.9)$ & 0 & 0 \\
\hline Mx/unknown & $140(28.8)$ & 0 & $226(100)$ \\
\hline \multicolumn{4}{|l|}{ Stage } \\
\hline I & $258(53.1)$ & $92(72.4)$ & $168(74.3)$ \\
\hline II & 116(23.9) & $35(27.6)$ & $58(25.7)$ \\
\hline III & 79(16.3) & 0 & 0 \\
\hline IV & $25(5.1)$ & 0 & 0 \\
\hline unknown & $8(1.6)$ & 0 & 0 \\
\hline Total & $486(100 \%)$ & $127(100 \%)$ & $226(100 \%)$ \\
\hline
\end{tabular}

\subsection{The establishment of seven immune-related IncRNAs signature}

The prognostic signature was constructed utilizing these 206 immune-related IncRNAs. 13 IncRNAs were picked out as candidate prognostic biomarkers to build the model at the p-value $<0.005$ (Fig. 1a)[31]. 12 IncRNAs were filtrated as vital factors after the logistic least absolute shrinkage and selection operator (Lasso regression, Fig. 1b, 1c). The risk model with seven IncRNAs (LINC00324, LINC01116, CASC15, LINC00857, CRNDE, GAS6-AS1 and LINC00460) was constructed through multivariable Cox analysis. The model was shown as follows: Risk score $=+0.240 \times$ LINC01116 + 0.213 $\times$ CASC15 + 0.247 $\times$ LINC00857 + $0.126 \times$ LINC00460-0.320 $\times$ LINC00324-0.126 × CRNDE - 0.328 × GAS6-AS1. In this model, LINC01116, CASC15, LINC00857 and LINC00460 were positive while LINC00324, CRNDE and GAS6-AS1 were negative correlated with this model.

\subsection{The seven IncRNAs were closely related with immune genes}

To explore the mechanism of the prognostic signature, the immune gene analysis of the seven IncRNAs was applied in the TCGA datasets and validated in the GEPIA2 database. Twenty immune genes were significantly correlated with the seven IncRNAs (absolute correlation coefficient $>0.4$ and p-value $<0.05$, Table 2), and the correlations were also confirmed in GEPIA2 analysis (Fig. 2a-t). 
Table 2

\begin{tabular}{|c|c|c|c|c|}
\hline IncRNA & immuneGene & correlation coefficient & p-value & Regulation \\
\hline \multirow[t]{6}{*}{ LINC00324 } & HLA-DMB & 0.401540092 & $3.81 \mathrm{E}-22$ & Positive \\
\hline & HLA-DRA & 0.409848373 & $4.35 \mathrm{E}-23$ & Positive \\
\hline & TPT1 & 0.453793307 & $1.55 \mathrm{E}-28$ & Positive \\
\hline & GMFG & 0.474826747 & $1.95 \mathrm{E}-31$ & Positive \\
\hline & CD48 & 0.576134718 & $1.23 \mathrm{E}-48$ & Positive \\
\hline & LST1 & 0.480046023 & $3.45 \mathrm{E}-32$ & Positive \\
\hline \multirow[t]{4}{*}{ LINC01116 } & S100A2 & 0.418392632 & 4.37E-24 & Positive \\
\hline & GCG & 0.512062763 & $4.28 \mathrm{E}-37$ & Positive \\
\hline & STC1 & 0.402735567 & $2.80 \mathrm{E}-22$ & Positive \\
\hline & VEGFC & 0.402222096 & 3.19E-22 & Positive \\
\hline \multirow[t]{4}{*}{ CASC15 } & IREB2 & 0.416866793 & $6.62 \mathrm{E}-24$ & Positive \\
\hline & LANCL1 & 0.435023719 & 4.13E-26 & Positive \\
\hline & PDK1 & 0.403436213 & 2.33E-22 & Positive \\
\hline & DPP8 & 0.407490161 & 8.10E-23 & Positive \\
\hline \multirow[t]{2}{*}{ GAS6-AS1 } & DDX17 & 0.418666649 & $4.06 \mathrm{E}-24$ & Positive \\
\hline & GNRH1 & 0.404965860 & $1.57 \mathrm{E}-22$ & Positive \\
\hline \multirow[t]{2}{*}{ LINC00460 } & CXCL5 & 0.427762637 & $3.26 \mathrm{E}-25$ & Positive \\
\hline & VEGFC & 0.423969477 & $9.42 \mathrm{E}-25$ & Positive \\
\hline LINC00857 & SEMA4G & 0.413201734 & $1.78 \mathrm{E}-23$ & Positive \\
\hline CRNDE & ZYX & -0.429172911 & 2.19E-25 & Negative \\
\hline
\end{tabular}

\subsection{The signature independently predicted LUAD prognosis}

To test the prognostic value of the model, the clinical information of both training group and validation groups were employed. According to the median immune risk score, the patients were divided into high risk group and low risk group. Using Kaplan-Meier survival analysis, the OS in high risk group was shorter than that in low risk group in the TCGA group (Fig. 3a), and similar results were obtained in two GEO datasets (Fig. 3b, 3c). Within this model, the mortality of patients increased in high risk score group with raised expression level of LINC01116, CASC15, LINC00857, LINC00460, albeit decreased LINC00324, CRNDE, GAS6-AS1 levels(Fig. 3d-f).

Clinicopathological features (such as age, gender, TNM and stage), individual IncRNA and seven-IncRNA signature were respectively analyzed for their correlations with OS by univariable and multivariable Cox regression methods in TCGA group. The risk score calculated from seven IncRNAs was significantly negative correlated with OS (Fig. 4a-b). And its value of prognosis predictor was also validated using the time-dependent ROC analysis with the area under the curve (AUC) of ROC curves showing $0.743,0.676$ and 0.842 in three datasets (Fig. 4c-e). Further results showed that the risk score was positively correlated with T, N, M pathologic stage, but was not with the advanced stage of T4 and N3, which may be interpreted by limited T4 or N3 cases in TCGA and no cases in GSE50081 and GSE 31210 (Fig. 5a-d).

\subsection{TIICs and immune pathways were related with the seven IncRNAs}

To investigate the immune cells and pathways involved in the seven IncRNAs, the ImmLnc database was performed in per IncRNA. From the TIICs inquiry, most frequent TIICs engaged in individual IncRNA in the seven-IncRNA signature (more than 4 IncRNAs) were B cells, Dendritic, Macrophage and CD 4 T cell (Table 3). And the immune pathways of Antigen Processing and Presentation, Chemokines, Cytokine Receptors, Cytokines and Antimicrobials were embroiled in three IncRNAs of the signature (LINC00460, GAS6-AS1 and LINC00857) (P adjust < 0.05 and absolute Score >0.995) (Table 4). 
Table 3

The relations between seven IncRNAs and six immune cells from ImmLnc database.

\begin{tabular}{|c|c|c|c|c|c|c|c|c|c|c|c|c|c|c|}
\hline \multirow[t]{2}{*}{ Immune Cell } & \multicolumn{2}{|c|}{ CASC15 } & \multicolumn{2}{|c|}{ CRNDE } & \multicolumn{2}{|c|}{ GAS6-AS1 } & \multicolumn{2}{|c|}{ LINC00324 } & \multicolumn{2}{|c|}{ LINC00460 } & \multicolumn{2}{|c|}{ LINC00857 } & \multicolumn{2}{|c|}{ LINC01116 } \\
\hline & $\begin{array}{l}\mathrm{P} \\
\text { Value }\end{array}$ & $\begin{array}{l}\text { Rs } \\
\text { Value }\end{array}$ & $\begin{array}{l}\mathrm{P} \\
\text { Value }\end{array}$ & $\begin{array}{l}\text { Rs } \\
\text { Value }\end{array}$ & $\begin{array}{l}\mathrm{P} \\
\text { Value }\end{array}$ & $\begin{array}{l}\text { Rs } \\
\text { Value }\end{array}$ & $\begin{array}{l}\mathrm{P} \\
\text { Value }\end{array}$ & $\begin{array}{l}\text { Rs } \\
\text { Value }\end{array}$ & $\begin{array}{l}\mathrm{P} \\
\text { Value }\end{array}$ & $\begin{array}{l}\text { Rs } \\
\text { Value }\end{array}$ & $\begin{array}{l}\mathrm{P} \\
\text { Value }\end{array}$ & $\begin{array}{l}\text { Rs } \\
\text { Value }\end{array}$ & $\begin{array}{l}\mathrm{P} \\
\text { Value }\end{array}$ & $\begin{array}{l}\text { Rs } \\
\text { Value }\end{array}$ \\
\hline B_cell & 0.04 & -0.091 & 0.549 & -0.027 & 0 & 0.343 & 0 & 0.28 & 0.047 & -0.088 & 0 & -0.288 & 0.245 & -0.052 \\
\hline CD4_Tcell & 0.149 & -0.064 & 0 & -0.202 & 0 & 0.35 & 0.01 & 0.113 & 0.918 & 0.005 & 0 & -0.198 & 0.568 & 0.025 \\
\hline CD8_Tcell & 0.401 & -0.037 & 0 & -0.281 & 0.97 & -0.002 & 0.002 & 0.138 & 0.861 & -0.008 & 0.44 & -0.034 & 0.766 & 0.013 \\
\hline Dendritic & 0.003 & -0.132 & 0 & -0.312 & 0 & 0.211 & 0.058 & 0.084 & 0.001 & 0.147 & 0 & -0.179 & 0.223 & 0.054 \\
\hline Macrophage & 0.893 & 0.006 & 0 & -0.241 & 0.002 & 0.135 & 0.03 & 0.096 & 0.915 & 0.005 & 0 & -0.156 & 0.019 & -0.104 \\
\hline Neutrophil & 0.807 & 0.011 & 0 & -0.411 & 0.006 & 0.121 & 0.803 & 0.011 & 0.104 & 0.072 & 0.106 & -0.072 & 0.005 & 0.124 \\
\hline
\end{tabular}

the

\begin{tabular}{|c|c|c|c|c|c|c|c|c|c|c|c|c|c|}
\hline \multirow{2}{*}{$\begin{array}{l}\text { Immune } \\
\text { Pathway }\end{array}$} & \multicolumn{5}{|c|}{ CASC15 } & \multicolumn{5}{|l|}{ CRNDE } & \multicolumn{3}{|c|}{ LINC01116 } \\
\hline & $\begin{array}{l}\mathrm{P} \\
\text { Value }\end{array}$ & $\begin{array}{l}\text { P } \\
\text { Adjust }\end{array}$ & ES & Score & $\begin{array}{l}\text { Marker } \\
\text { Gene } \\
\text { Number }\end{array}$ & $\begin{array}{l}\mathrm{P} \\
\text { Value }\end{array}$ & $\begin{array}{l}\text { P } \\
\text { Adjust }\end{array}$ & ES & Score & $\begin{array}{l}\text { Marker } \\
\text { Gene } \\
\text { Number }\end{array}$ & $\begin{array}{l}\mathrm{P} \\
\text { Value }\end{array}$ & $\begin{array}{l}\text { P } \\
\text { Adjust }\end{array}$ & ES \\
\hline $\begin{array}{l}\text { Antigen } \\
\text { Processing } \\
\text { and } \\
\text { Presentation }\end{array}$ & 0.0026 & 0.0253 & -0.6790 & -0.9948 & 39 & 0.0201 & 0.3410 & -0.4095 & -0.9599 & 37 & 0.3777 & 0.7135 & 0.3134 \\
\hline Antimicrobials & 0.0030 & 0.0253 & -0.3676 & -0.9940 & 119 & 0.7256 & 0.9780 & -0.2441 & 0.4513 & 105 & 0.3408 & 0.7135 & -0.2489 \\
\hline $\begin{array}{l}\text { BCR Signaling } \\
\text { Pathway }\end{array}$ & 0.0512 & 0.2177 & -0.4362 & -0.8976 & 18 & 0.9204 & 0.9780 & -0.2506 & 0.8408 & 8 & 0.2264 & 0.7135 & -0.3341 \\
\hline $\begin{array}{l}\text { Chemokine } \\
\text { Receptors }\end{array}$ & 0.3805 & 0.4976 & -0.3621 & -0.2390 & 9 & 0.9003 & 0.9780 & 0.2741 & -0.8007 & 15 & 0.0130 & 0.1104 & -0.5329 \\
\hline Chemokines & 0.1531 & 0.3875 & -0.3524 & -0.6938 & 12 & 0.2431 & 0.8061 & -0.3433 & -0.5138 & 31 & 0.6600 & 0.8630 & 0.2886 \\
\hline $\begin{array}{l}\text { Cytokine } \\
\text { Receptors }\end{array}$ & 0.0836 & 0.2841 & -0.3024 & -0.8329 & 66 & 0.1739 & 0.7761 & 0.3275 & 0.6523 & 94 & 0.0045 & 0.0762 & -0.4004 \\
\hline Cytokines & 0.4632 & 0.5250 & -0.2553 & -0.0736 & 55 & 0.9805 & 0.9805 & 0.2281 & -0.9609 & 71 & 0.0568 & 0.3218 & 0.3302 \\
\hline $\begin{array}{l}\text { Interferon } \\
\text { Receptor }\end{array}$ & 0.2280 & 0.3875 & -0.7831 & -0.5441 & 2 & 0.4767 & 0.9780 & 0.6769 & 0.0466 & 3 & 0.6189 & 0.8630 & -0.5997 \\
\hline Interferons & 0.7216 & 0.7667 & 0.6402 & -0.4431 & 1 & 0.4828 & 0.9780 & -0.7476 & -0.0345 & 1 & 0.7467 & 0.9067 & 0.6318 \\
\hline Interleukins & 0.9688 & 0.9688 & 0.2416 & -0.9376 & 3 & 0.8684 & 0.9780 & 0.2899 & -0.7368 & 8 & 0.9400 & 0.9971 & -0.2504 \\
\hline $\begin{array}{l}\text { Interleukins } \\
\text { Receptor }\end{array}$ & 0.3104 & 0.4398 & -0.3763 & -0.3792 & 10 & 0.5285 & 0.9780 & -0.3396 & 0.0571 & 7 & 0.3728 & 0.7135 & -0.3599 \\
\hline $\begin{array}{l}\text { Natural Killer } \\
\text { Cell } \\
\text { Cytotoxicity }\end{array}$ & 0.0050 & 0.0283 & -0.5044 & -0.9900 & 24 & 0.1826 & 0.7761 & -0.3373 & -0.6348 & 35 & 0.9971 & 0.9971 & 0.1958 \\
\hline $\begin{array}{l}\text { TCR signaling } \\
\text { Pathway }\end{array}$ & 0.4521 & 0.5250 & -0.2975 & -0.0958 & 18 & 0.2845 & 0.8061 & -0.3337 & -0.4310 & 19 & 0.8189 & 0.9281 & -0.2441 \\
\hline $\begin{array}{l}\text { TGFb Family } \\
\text { Member }\end{array}$ & 0.1820 & 0.3875 & 0.4557 & 0.6360 & 7 & 0.1174 & 0.7761 & 0.5124 & 0.7653 & 9 & 0.3442 & 0.7135 & 0.4194 \\
\hline $\begin{array}{l}\text { TGFb Family } \\
\text { Member } \\
\text { Receptor }\end{array}$ & 0.1982 & 0.3875 & 0.5762 & 0.6037 & 6 & 0.7094 & 0.9780 & 0.3879 & -0.4189 & 7 & 0.3126 & 0.7135 & -0.5060 \\
\hline $\begin{array}{l}\text { TNF Family } \\
\text { Members }\end{array}$ & 0.3063 & 0.4398 & -0.5134 & -0.3873 & 3 & 0.8681 & 0.9780 & 0.3269 & -0.7362 & 4 & 0.5093 & 0.8630 & $-0.437 \varepsilon$ \\
\hline $\begin{array}{l}\text { TNF Family } \\
\text { Members } \\
\text { Receptors }\end{array}$ & 0.2196 & 0.3875 & -0.4898 & -0.5608 & 6 & 0.8759 & 0.9780 & -0.3006 & 0.7519 & 5 & 0.6335 & 0.8630 & 0.3726 \\
\hline
\end{tabular}

\subsection{The signature was closely correlated with TIICs and immune pathways}

As the immune genes and TIICs were correlated with our included IncRNAs, we further quantified the TIICs within the two risk groups by the Cibersortx analysis. The result suggested that high risk group had a greater infiltration level of T cells CD4 memory activated, NK cells resting, Macrophages M0 and M1 and Mast cells activated, while less of T cells CD 4 memory resting, Monocytes, Dendritic cells resting and Mast cells resting were found ( $P<0.01$, Fig. $6 a)$. 
In order to explore the correlation between the model and immune microenvironment, GSEA analysis of the immunological signatures was carried out between high and low risk groups in the TCGA datasets. Within the 4872 gene sets of high risk group, $59.36 \%$ of them were significantly enriched at the false discovery rate $(\mathrm{FDR})<25 \%$, while $23.20 \%$ were significant at nominal p-value $<1 \%$ and $38.94 \%$ were at nominal p-value $<5 \%$. In the low risk group, $39.94 \%$ gene sets were enriched at FDR $<25 \%, 9.48 \%$ of them were at nominal p-value $<1 \%$ and $20.22 \%$ at nominal p-value $<5 \%$. Contrastly, the high risk group was distinctly enriched in the immunological signatures, especially in the pathways of macrophage and CD4 T cells (Fig. 6b-g).

\section{Discussion}

Lung adenocarcinoma is a deadly malignancy, which is prone to local relapse and distant metastasis[2]. Besides genetic abnormality delineating the process of cancer, IncRNAs are gradually concerned for their increasing role in the progression of cancer. LncRNAs are long-term studied for their role of promoting proliferation and metastasis in the progression of LUAD [32], but it is still lack of IncRNAs model in predicting LUAD prognosis.

In this study, we constructed a seven IncRNAs model as a prognostic signature for LUAD. We first screened out 206 immune-related IncRNAs using Pearson correlation analysis between IncRNAs and immune genes, and then construct a seven IncRNAs signature via Cox proportional hazards regression and logistic least absolute shrinkage and selection operator. High and low risk groups were split by the median risk score among LUAD patients from each cohort, and poorer overall survival of the high-risk group were validated in both TCGA and two GEO datasets. Further we unraveled that more infiltration of activated memory CD4 T cells, resting NK cells, Macrophages MO and activated Mast cells, and less of Monocytes, resting Dendritic cells and resting Mast cells were discovered in high-risk group. Immune pathways related to Macrophage and memory CD4 T cell were also significantly enriched in the high-risk patients.

Immune destruction and recruited immune cells to tumor site are emerging hallmarks in cancer[33]. Immune microenvironment is composed of different immune cells including various populations of T cells, B cells, dendritic cells, natural killer (NK) cells, neutrophils and macrophages. The density and distribution of immune cells within solid tumors which decide the immune texture and immune contexture can shape cancer destiny[34]. TIICs are considered as active players in cancer progression and cause heterogeneous responses to variant treatments[35].

LncRNAs play vital roles in the function of immune cells within tumors[16, 36]. Here we found that all the seven IncRNAs were closely associated with TIICs, and the most relevant TIICs were B cells, macrophage, neutrophils and Dendritic cells. Antigen-present is an important process for anti-tumor immune reaction. Immune pathways especially Antigen Processing and Presentation involved in the seven IncRNAs and signature are deeply engaged in the recruitment of TIICs and cancer development. Our study indicated that immune pathways related to macrophage and memory CD4 T cell were distinctly enriched in high risk groups.

Various IncRNAs were reported being predictors in the prognosis of B-cell lymphoma via stimulation or inhibition role on B cells. Macrophage is a vital participant in the process of Antigen Processing and Presentation and immunotherapy [37]. It can be regulated by several IncRNAs[38]. Macrophages originate from monocytes of bloodstream and becoming TAMs after migration. TAMs drive disease to deteriorate via promoting cancer metastasis in early-stage lung cancer[39]. LncRNAs participate in the development and polarization of macrophages, which might showed big impact on cancer progression and the efficacy of PD-L1 antibody[36]. Neutrophils hold the bidirectional traits in promoting or averting cancer progression, and were also identified in our studies to be relevant to IncRNAs. Dendritic cells are specialized as antigen-presenting cells serving immune process, and their interaction with tumor cells are presented as immune-activator or immune-suppressor during cancer progression, which can be regulated by IncRNAs[40]. Among the seven IncRNAs, CRNDE, GAS6-AS1, LINC00324 and LINC00857 have the most intimate connection with these TIICs $(p<0.05$ and absolute Rs value $>0.2)$. LncRNA colorectal neoplasia differentially expressed (CRNDE) promotes proliferations and metastasis by instigating suppressor TIICs.

Prominently, within tumor microenvironment (TME), infiltrating T cells are the strongest predictor for PD-L1 efficacy. We found that high risk group had a greater infiltration level of T cells CD4 memory activated, while less of T cells CD4 memory resting. T cells can also be recruited by chemokines into cancer area from circulation [34]. Intriguingly, decreased LINC00324 might lead to immune evasion of cancer cells through defective NK cells via inhibiting immune pathways of cytokine and chemokine signaling and Ag processing[41-44]. Noticeably, LINC00460 was enriched in four immune pathways by the ImmLnc analysis, indicating its critical role in immune system. C-X-C motif chemokine ligand 5 (CXCL5) which was closely correlated with LINC00460 in the signature could increase PD-L1 expression via PI3K/AKT pathway [45] and regulate the function of tumor-associated neutrophils which inhibit the activities of Th1 and Th17, CTLs and NK cells[46-49]. Similarly, VEGFC/VEGFR3 signaling closely connected with LINC01116 and LINC00460 were mainly expressed on immune cells including macrophages and NK cells, and might also disturb ICB efficacy via affecting dendritic cells and CD8 T cells [50-52], or inducing the naïve T cells via CCL21[53].

Some limitations remained in our study. Firstly, lacking of detailed information on clinical therapeutics would confound the role of this seven IncRNAs signature in predicting the OS of LUAD. Secondly, TIICs diversification in tumor-related immune environment obscured the mechanism underlying the high risk group with poor OS attributed to immune escape or privilege. Thirdly, the seven IncRNAs signature was correlated with $\mathrm{T}$ and $\mathrm{N}$ except $\mathrm{M}$, since limited cases in the included public datasets. Fourthly, no further experiments in vivo and vitro limited the convincingness of the conclusions and clinic values.

\section{Conclusion}

Collectively, we identified a seven IncRNAs prognostic signature, indicating that high risk patients have poor prognosis. High risk group showed more infiltration of activated memory CD4 T cells, resting NK cells, Macrophages M0, activated Mast cells and less of Monocytes, resting Dendritic cells and resting Mast cells, probably correlated with immune-escape phenotype. So this seven IncRNAs signature hold the potential to become an alternative marker and novel targets in the prognosis predictor and immune therapy of LUAD. 


\section{Abbreviations}

LUAD, lung adenocarcinoma; IncRNAs, long non-coding RNAs; TIICs, tumor-infiltrating immune cells; TCGA, The Cancer Genome Atlas; GEO, Gene Expression Omnibus; OS, overall survival; NSCLC, non-small cell lung cancer; ICB, immune checkpoint blockade; PD-L1, programmed death-ligand 1; CTLs, cytotoxic T lymphocytes; TAMs, tumor-associated macrophages; eTreg cells, effector Regulatory T cells; HPD, hyperprogressive disease; G-MDSCs, granulocytic myeloidderived suppressor cells; TH1cells, type 1 helper T cells; FPKM, fragments per kilobase of exon per-million fragments; GDC, Genomic Data Commons; GEPIA2, Gene Expression Profiling Interactive Analysis; ANOVA, Analysis of Variance; ROC curve, receiver operating characteristic curve; AUC, area under the curve; GSEA, gene set enrichment analysis; RMA, Robust Multiarray Average; FDR, false discovery rate; ncRNAs, non-coding RNAs; PD-1, programmed death 1; CRNDE, colorectal neoplasia differentially expressed; TME, tumor microenvironment; CXCL5, C-X-C motif chemokine ligand 5; NK cells, natural killer cells.

\section{Declarations}

\section{Author contributions}

$\mathrm{BL}, \mathrm{CD}$, and $\mathrm{CZ}$ designed andrevisedthe manuscript. JWwas responsible for the acquisition and disposal of data and draft ofthe manuscript. YM contributedto the literature searchanddiscussion.All authorsread and approved the final manuscript and agreed to beaccountable for theaccuracy and integrity of the research.

\section{Author details}

${ }^{1}$ Department of Oncology, Xiangya Hospital, Central South University, Changsha 410008, PR China; ${ }^{2}$ Hunan Engineering Research Center for Pulmonary Nodules Precise Diagnosis \& Treatment, Department of Thoracic Surgery, Xiangya Hospital, Central South University, Changsha $410008, \mathrm{PR}$ China; ${ }^{3}$ Institute of Medical Sciences, Xiangya Hospital, Central South University, Changsha, 410008, PR China; ${ }^{4}$ National Clinical Research Center for Geriatric Disorders, Xiangya Hospital, Central South University, Changsha 410008, PR China.

\section{Acknowledgements}

Not applicable.

\section{Competing interests}

The authors declare that they have no competing interests

\section{Availability of data and materials}

Data sharing is not applicable to this article as all datasets supporting the conclusions are obtained from public repositories and/or included within the manuscript.

\section{Consent for publication}

Not applicable.

\section{Ethics approval and consent to participate}

Not applicable.

\section{Funding}

This work was granted by the National NaturalScience Foundation of China $(81200366,81572281,81702278,81974367)$ and Province Natural Science Foundation of Hunan(No. 14JJ6004) and the Key Subject Education Department ofHunan ([2012]594) and Scientific Research Project of Hunan Provincial Department of Education (No. 18K001).

\section{References}

1. Bray F, Ferlay J, Soerjomataram I, Siegel RL, Torre LA, Jemal A. Global cancer statistics 2018: GLOBOCAN estimates of incidence and mortality worldwide for 36 cancers in 185 countries. CA Cancer J Clin. 2018;68:394-424.

2. Shi J, Hua X, Zhu B, Ravichandran S, Wang M, Nguyen C, Brodie SA, Palleschi A, Alloisio M, Pariscenti G, et al. Somatic Genomics and Clinical Features of Lung Adenocarcinoma: A Retrospective Study. PLoS Med. 2016;13:e1002162.

3. Borghaei H, Paz-Ares L, Horn L, Spigel DR, Steins M, Ready NE, Chow LQ, Vokes EE, Felip E, Holgado E, et al. Nivolumab versus Docetaxel in Advanced Nonsquamous Non-Small-Cell Lung Cancer. N Engl J Med. 2015;373:1627-39.

4. Sabari JK, Leonardi GC, Shu CA, Umeton R, Montecalvo J, Ni A, Chen R, Dienstag J, Mrad C, Bergagnini I, et al. PD-L1 expression, tumor mutational burden, and response to immunotherapy in patients with MET exon 14 altered lung cancers. Ann Oncol. 2018;29:2085-91.

5. Arbour KC, Riely GJ. Systemic Therapy for Locally Advanced and Metastatic Non-Small Cell Lung Cancer: A Review. JAMA. 2019;322:764-74.

6. Camidge DR, Doebele RC, Kerr KM. Comparing and contrasting predictive biomarkers for immunotherapy and targeted therapy of NSCLC. Nat Rev Clin Oncol. 2019;16:341-55. 
7. Jiang P, Gu S, Pan D, Fu J, Sahu A, Hu X, Li Z, Traugh N, Bu X, Li B, et al. Signatures of T cell dysfunction and exclusion predict cancer immunotherapy response. Nat Med. 2018;24:1550-58.

8. Denkert C, von Minckwitz G, Darb-Esfahani S, Lederer B, Heppner BI, Weber KE, Budczies J, Huober J, Klauschen F, Furlanetto J, et al. Tumour-infiltrating lymphocytes and prognosis in different subtypes of breast cancer: a pooled analysis of 3771 patients treated with neoadjuvant therapy. Lancet Oncol. 2018;19:40-50.

9. Lo Russo G, Moro M, Sommariva M, Cancila V, Boeri M, Centonze G, Ferro S, Ganzinelli M, Gasparini P, Huber V, et al. Antibody-Fc/FcR Interaction on Macrophages as a Mechanism for Hyperprogressive Disease in Non-small Cell Lung Cancer Subsequent to PD-1/PD-L1 Blockade. Clin Cancer Res. 2019;25:989-99.

10. Arasanz H, Zuazo M, Bocanegra A, Gato M, Martinez-Aguillo M, Morilla I, Fernandez G, Hernandez B, Lopez P, Alberdi N, et al. Early Detection of Hyperprogressive Disease in Non-Small Cell Lung Cancer by Monitoring of Systemic T Cell Dynamics. Cancers (Basel) $2020,12$.

11. Kim CG, Kim KH, Pyo KH, Xin CF, Hong MH, Ahn BC, Kim Y, Choi SJ, Yoon HI, Lee JG, et al. Hyperprogressive disease during PD-1/PD-L1 blockade in patients with non-small-cell lung cancer. Ann Oncol. 2019;30:1104-13.

12. Sabio E, Chan TA. The good, the bad, and the ugly: hyperprogression in cancer patients following immune checkpoint therapy. Genome Med. $2019 ; 11: 43$.

13. Kim Y, Kim CH, Lee HY, Lee SH, Kim HS, Lee S, Cha H, Hong S, Kim K, Seo SW, et al. Comprehensive Clinical and Genetic Characterization of Hyperprogression Based on Volumetry in Advanced Non-Small Cell Lung Cancer Treated With Immune Checkpoint Inhibitor. J Thorac Oncol. 2019;14:1608-18.

14. Cheng J, Meng J, Zhu L, Peng Y. Exosomal noncoding RNAs in Glioma: biological functions and potential clinical applications. Mol Cancer. 2020;19:66.

15. Zhang L, Xu X, Su X. Noncoding RNAs in cancer immunity: functions, regulatory mechanisms, and clinical application. Mol Cancer. 2020;19:48.

16. Huang D, Chen J, Yang L, Ouyang Q, Li J, Lao L, Zhao J, Liu J, Lu Y, Xing Y, et al. NKILA IncRNA promotes tumor immune evasion by sensitizing T cells to activation-induced cell death. Nat Immunol. 2018;19:1112-25.

17. NE II, Heward JA, Roux B, Tsitsiou E, Fenwick PS, Lenzi L, Goodhead I, Hertz-Fowler C, Heger A, Hall N, et al. Long non-coding RNAs and enhancer RNAs regulate the lipopolysaccharide-induced inflammatory response in human monocytes. Nat Commun. 2014;5:3979.

18. Cui H, Banerjee S, Guo S, Xie N, Ge J, Jiang D, Zornig M, Thannickal VJ, Liu G. Long noncoding RNA Malat1 regulates differential activation of macrophages and response to lung injury. JCl Insight 2019, 4.

19. Zheng Y, Tian X, Wang T, Xia X, Cao F, Tian J, Xu P, Ma J, Xu H, Wang S. Long noncoding RNA Pvt1 regulates the immunosuppression activity of granulocytic myeloid-derived suppressor cells in tumor-bearing mice. Mol Cancer. 2019;18:61.

20. Chen F, Chen J, Yang L, Liu J, Zhang X, Zhang Y, Tu Q, Yin D, Lin D, Wong PP, et al. Extracellular vesicle-packaged HIF-1alpha-stabilizing IncRNA from tumour-associated macrophages regulates aerobic glycolysis of breast cancer cells. Nat Cell Biol. 2019;21:498-510.

21. Barrett T, Wilhite SE, Ledoux P, Evangelista C, Kim IF, Tomashevsky M, Marshall KA, Phillippy KH, Sherman PM, Holko M, et al. NCBI GEO: archive for functional genomics data sets-update. Nucleic Acids Res. 2013;41:D991-5.

22. Okayama H, Kohno T, Ishii Y, Shimada Y, Shiraishi K, Iwakawa R, Furuta K, Tsuta K, Shibata T, Yamamoto S, et al. Identification of genes upregulated in ALK-positive and EGFR/KRAS/ALK-negative lung adenocarcinomas. Cancer Res. 2012;72:100-11.

23. Yamauchi M, Yamaguchi R, Nakata A, Kohno T, Nagasaki M, Shimamura T, Imoto S, Saito A, Ueno K, Hatanaka Y, et al. Epidermal growth factor receptor tyrosine kinase defines critical prognostic genes of stage I lung adenocarcinoma. PLoS One. 2012;7:e43923.

24. Der SD, Sykes J, Pintilie M, Zhu CQ, Strumpf D, Liu N, Jurisica I, Shepherd FA, Tsao MS. Validation of a histology-independent prognostic gene signature for early-stage, non-small-cell lung cancer including stage IA patients. J Thorac Oncol. 2014;9:59-64.

25. Wei C, Liang Q, Li X, Li H, Liu Y, Huang X, Chen X, Guo Y, Li J. Bioinformatics profiling utilized a nine immune-related long noncoding RNA signature as a prognostic target for pancreatic cancer. J Cell Biochem. 2019;120:14916-27.

26. Bhattacharya S, Dunn P, Thomas CG, Smith B, Schaefer H, Chen J, Hu Z, Zalocusky KA, Shankar RD, Shen-Orr SS, et al. ImmPort, toward repurposing of open access immunological assay data for translational and clinical research. Sci Data. 2018;5:180015.

27. Subramanian A, Tamayo P, Mootha VK, Mukherjee S, Ebert BL, Gillette MA, Paulovich A, Pomeroy SL, Golub TR, Lander ES, Mesirov JP. Gene set enrichment analysis: a knowledge-based approach for interpreting genome-wide expression profiles. Proc Natl Acad Sci U S A. 2005;102:15545-50.

28. Tang Z, Kang B, Li C, Chen T, Zhang Z. GEPIA2: an enhanced web server for large-scale expression profiling and interactive analysis. Nucleic Acids Res. 2019;47:W556-W60.

29. Li Y, Jiang T, Zhou W, Li J, Li X, Wang Q, Jin X, Yin J, Chen L, Zhang Y, et al. Pan-cancer characterization of immune-related IncRNAs identifies potential oncogenic biomarkers. Nat Commun. 2020;11:1000.

30. Newman AM, Steen CB, Liu CL, Gentles AJ, Chaudhuri AA, Scherer F, Khodadoust MS, Esfahani MS, Luca BA, Steiner D, et al. Determining cell type abundance and expression from bulk tissues with digital cytometry. Nat Biotechnol. 2019;37:773-82.

31. Yang G, Zhang Y, Yang J. A Five-microRNA Signature as Prognostic Biomarker in Colorectal Cancer by Bioinformatics Analysis. Front Oncol. 2019;9:1207.

32. Qian H, Chen L, Huang J, Wang X, Ma S, Cui F, Luo L, Ling L, Luo K, Zheng G. The IncRNA MIR4435-2HG promotes lung cancer progression by activating beta-catenin signalling. J Mol Med (Berl). 2018;96:753-64.

33. Ferrari SM, Fallahi P, Galdiero MR, Ruffilli I, Elia G, Ragusa F, Paparo SR, Patrizio A, Mazzi V, Varricchi G, et al. Immune and Inflammatory Cells in Thyroid Cancer Microenvironment. Int J Mol Sci 2019, 20.

34. Remark R, Becker C, Gomez JE, Damotte D, Dieu-Nosjean MC, Sautes-Fridman C, Fridman WH, Powell CA, Altorki NK, Merad M, Gnjatic S. The non-small cell lung cancer immune contexture. A major determinant of tumor characteristics and patient outcome. Am J Respir Crit Care Med. 2015;191:377-90. 
35. Liu X, Wu S, Yang Y, Zhao M, Zhu G, Hou Z. The prognostic landscape of tumor-infiltrating immune cell and immunomodulators in lung cancer. Biomed Pharmacother. 2017;95:55-61.

36. Vishnubalaji R, Shaath H, Elango R, Alajez NM. Noncoding RNAs as potential mediators of resistance to cancer immunotherapy. Semin Cancer Biol 2019.

37. DeNardo DG, Ruffell B. Macrophages as regulators of tumour immunity and immunotherapy. Nat Rev Immunol. 2019;19:369-82.

38. Hu Q, Ye Y, Chan LC, Li Y, Liang K, Lin A, Egranov SD, Zhang Y, Xia W, Gong J, et al. Oncogenic IncRNA downregulates cancer cell antigen presentation and intrinsic tumor suppression. Nat Immunol. 2019;20:835-51.

39. Singhal S, Stadanlick J, Annunziata MJ, Rao AS, Bhojnagarwala PS, O'Brien S, Moon EK, Cantu E, Danet-Desnoyers G, Ra HJ, et al. Human tumorassociated monocytes/macrophages and their regulation of T cell responses in early-stage lung cancer. Sci Trans/ Med $2019,11$.

40. Chen J, Wang S, Jia S, Ding G, Jiang G, Cao L. Integrated Analysis of Long Non-Coding RNA and mRNA Expression Profile in Pancreatic Cancer Derived Exosomes Treated Dendritic Cells by Microarray Analysis. J Cancer. 2018;9:21-31.

41. Khaznadar Z, Boissel N, Agaugue S, Henry G, Cheok M, Vignon M, Geromin D, Cayuela JM, Castaigne S, Pautas C, et al. Defective NK Cells in Acute Myeloid Leukemia Patients at Diagnosis Are Associated with Blast Transcriptional Signatures of Immune Evasion. J Immunol. 2015;195:2580-90.

42. Elias S, Yamin R, Golomb L, Tsukerman P, Stanietsky-Kaynan N, Ben-Yehuda D, Mandelboim O. Immune evasion by oncogenic proteins of acute myeloid leukemia. Blood. 2014;123:1535-43.

43. Wang Z, Xiao Y, Guan W, Wang M, Chen J, Zhang L, Li Y, Xiong Q, Wang H, Wang M, et al. Acute myeloid leukemia immune escape by epigenetic CD48 silencing. Clin Sci (Lond). 2020;134:261-71.

44. Huang $\mathrm{CH}$, Liao YJ, Chiou TJ, Huang HT, Lin YH, Twu YC. TGF-beta regulated leukemia cell susceptibility against NK targeting through the downregulation of the CD48 expression. Immunobiology. 2019;224:649-58.

45. Li Z, Zhou J, Zhang J, Li S, Wang H, Du J. Cancer-associated fibroblasts promote PD-L1 expression in mice cancer cells via secreting CXCL5. Int J Cancer. 2019;145:1946-57.

46. Zhang D, Zhou J, Tang D, Zhou L, Chou L, Chou KY, Tao L, Lu LM. Neutrophil infiltration mediated by CXCL5 accumulation in the laryngeal squamous cell carcinoma microenvironment: A mechanism by which tumour cells escape immune surveillance. Clin Immunol. 2017;175:34-40.

47. Forsthuber A, Lipp K, Andersen L, Ebersberger S, Grana C, Ellmeier W, Petzelbauer P, Lichtenberger BM, Loewe R. CXCL5 as Regulator of Neutrophil Function in Cutaneous Melanoma. J Invest Dermatol. 2019;139:186-94.

48. Fan X, Guo D, Cheung AMS, Poon ZY, Yap CS, Goh SE, Guo D, Li H, Bari S, Li S, et al. Mesenchymal Stromal Cell (MSC)-Derived Combination of CXCL5 and Anti-CCL24 Is Synergistic and Superior to MSC and Cyclosporine for the Treatment of Graft-versus-Host Disease. Biol Blood Marrow Transplant. 2018;24:1971-80.

49. Li BH, Garstka MA, Li ZF. Chemokines and their receptors promoting the recruitment of myeloid-derived suppressor cells into the tumor. Mol Immunol. 2020;117:201-15.

50. Tacconi C, Ungaro F, Correale C, Arena V, Massimino L, Detmar M, Spinelli A, Carvello M, Mazzone M, Oliveira Al, et al. Activation of the VEGFC/VEGFR3 Pathway Induces Tumor Immune Escape in Colorectal Cancer. Cancer Res. 2019;79:4196-210.

51. Wang CA, Tsai SJ. The non-canonical role of vascular endothelial growth factor-C axis in cancer progression. Exp Biol Med (Maywood). 2015;240:71824.

52. Hsu MC, Pan MR, Hung WC. Two Birds, One Stone: Double Hits on Tumor Growth and Lymphangiogenesis by Targeting Vascular Endothelial Growth Factor Receptor 3. Cells 2019, 8.

53. Fankhauser M, Broggi MAS, Potin L, Bordry N, Jeanbart L, Lund AW, Da Costa E, Hauert S, Rincon-Restrepo M, Tremblay C, et al. Tumor lymphangiogenesis promotes T cell infiltration and potentiates immunotherapy in melanoma. Sci Trans/ Med 2017, 9.

\section{Figures}


$\mathbf{a}$

$\begin{array}{lrr}\text { pvalue } & \begin{array}{r}\text { Hazard ratio } \\ \text { LINC00324 }\end{array} \\ \text { LINC00996 } & 0.001 & 0.551(0.383-0.794) \\ \text { LINC01116 } & <0.001 & 0.519(0.330-0.815) \\ \text { COLCA1 } & 0.003 & 0.758(1.245-1.730) \\ \text { CASC15 } & <0.001 & 1.439(1.175-1.762) \\ \text { LINC00857 } & <0.001 & 1.587(1.236-2.039) \\ \text { CRNDE } & <0.001 & 0.713(0.611-0.832) \\ \text { GAS6-AS1 } & 0.002 & 0.613(0.450-0.837) \\ \text { LINC00460 } & 0.002 & 1.208(1.071-1.363) \\ \text { TMPO-AS1 } & <0.001 & 1.721(1.274-2.324) \\ \text { RBPMS-AS1 } & 0.003 & 0.717(0.575-0.894) \\ \text { RPARP-AS1 } & 0.003 & 0.631(0.467-0.852) \\ \text { ARHGEF26-AS10.004 } & 0.614(0.439-0.858)\end{array}$

b

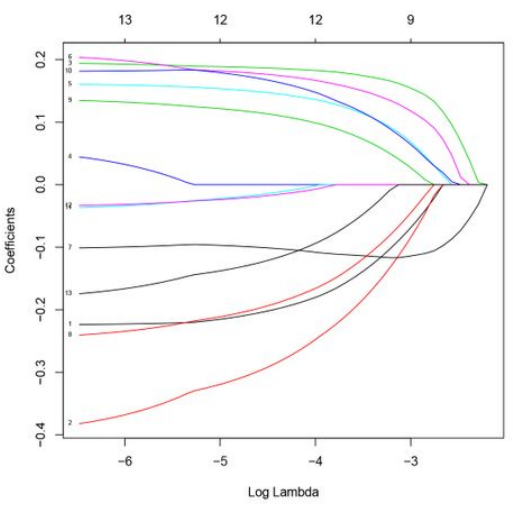

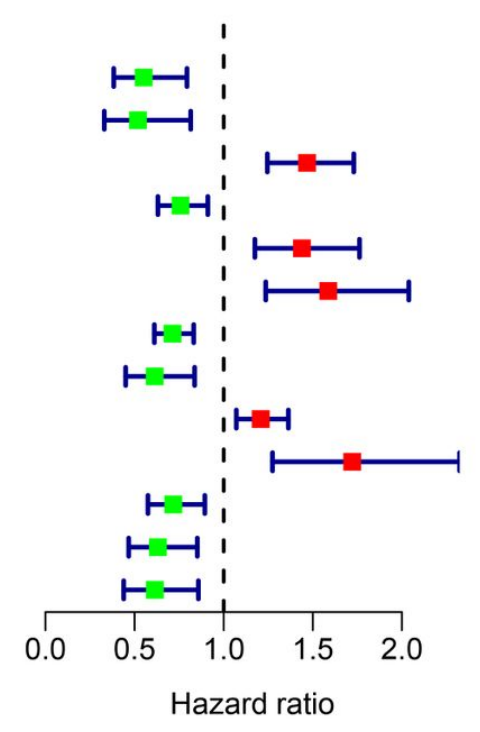

C

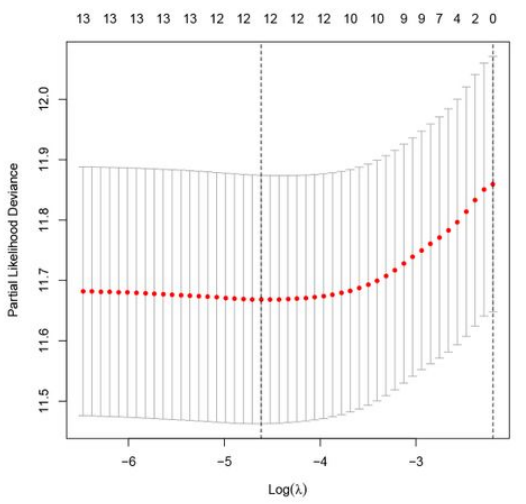

Figure 1

Construction of the prognostic IncRNA signature in the TCGA group.Alternative 13 prognostic IncRNAs (a); The coefficients(b) and vertical blue dotted lines(c) of the 13 IncRNAs in Lasso regression. 

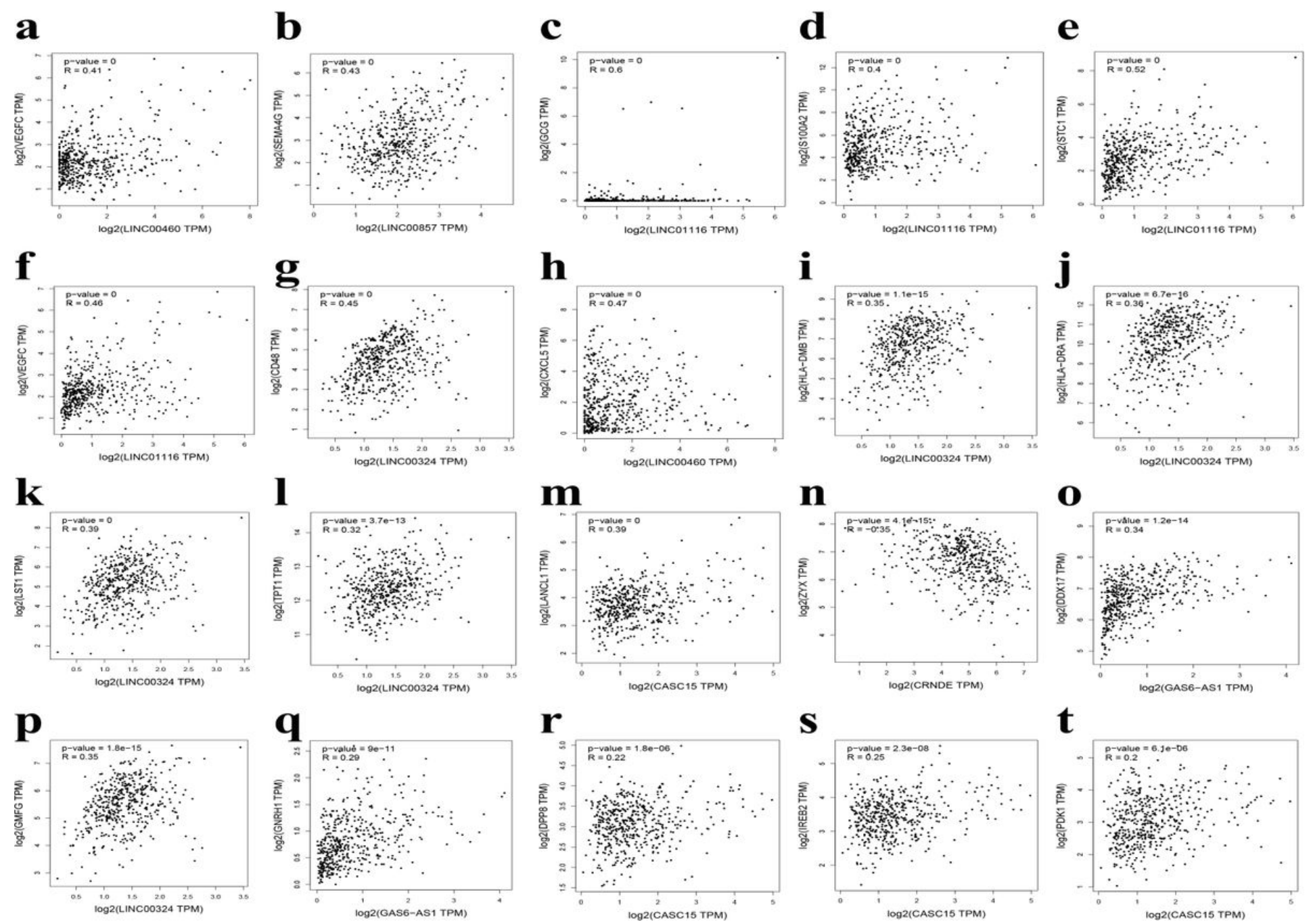

Figure 2

The scatter diagrams of related immune gene and IncRNAs in the GEPIA2 databases. 

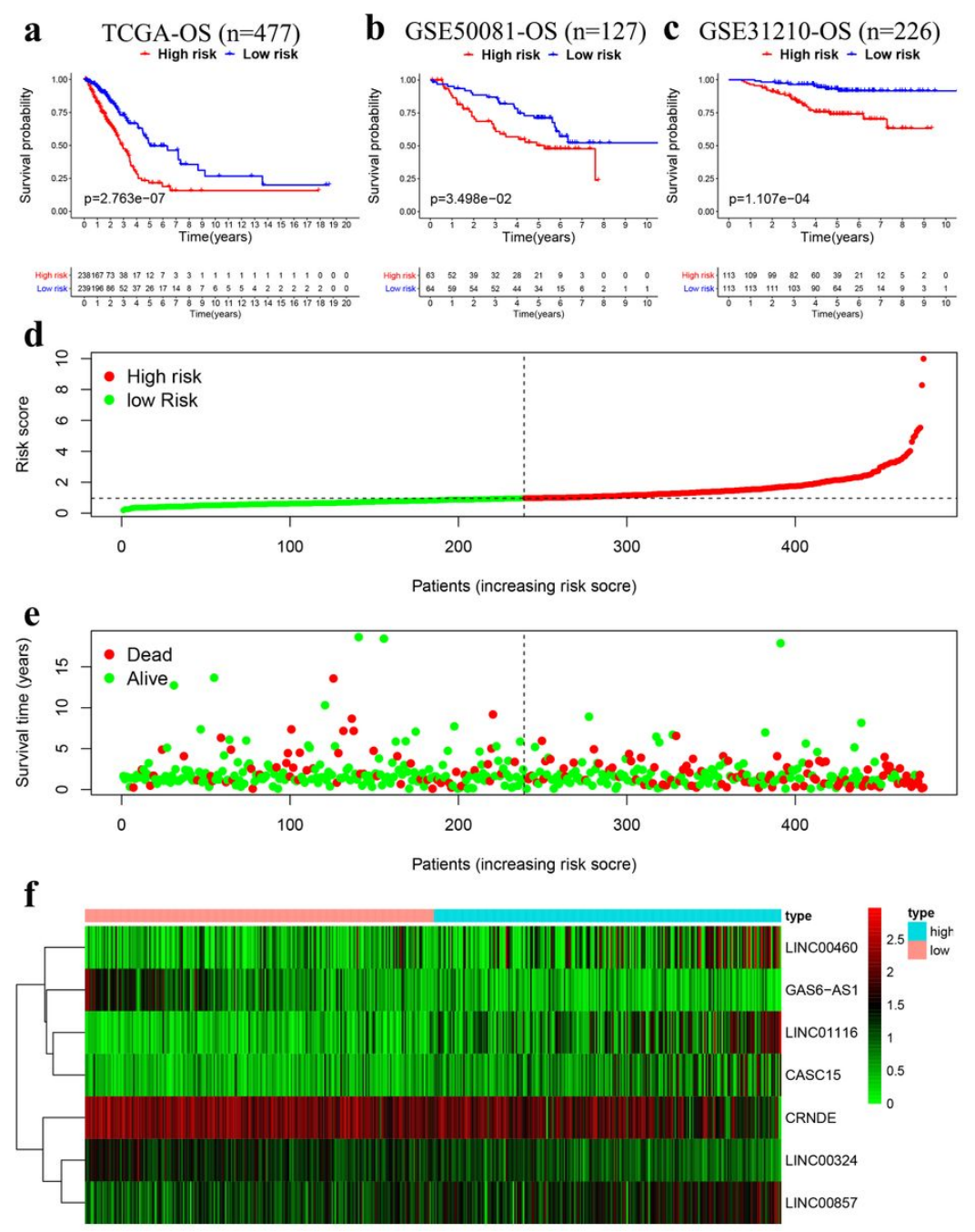

Figure 3

Survival analyses of two risk groups defined by the seven IncRNAs signature. The Kaplan-Meier survival curves of the overall survival from TCGA(a), GSE50081(b) and GSE31210(c) datasets. The risk score distribution(d), survival status of the patients(e) and heatmap of the seven IncRNAs (f) of the seven IncRNAs signature of the TCGA datasets. 
a

$\begin{array}{lrr} & \text { pvalue } & \begin{array}{r}\text { Hazard ratio } \\ \text { age }\end{array} \\ \text { gender } & 0.718 & 0.997(0.978-1.015) \\ \text { stage } & 1.000 & 1.000(0.694-1.441) \\ T & <0.001 & 1.648(1.396-1.946) \\ \mathrm{M} & <0.001 & 1.600(1.285-1.994) \\ \mathrm{N} & 0.068 & 1.748(0.959-3.187) \\ \text { LINC00324 } & <0.001 & 1.787(1.455-2.195) \\ \text { LINC01116 } & <0.001 & 1.438(1.192-1.735) \\ \text { CASC15 } & 0.002 & 1.425(1.142-1.778) \\ \text { LINC00857 } & 0.110 & 1.274(0.946-1.715) \\ \text { CRNDE } & <0.001 & 0.732(0.618-0.868) \\ \text { GAS6-AS1 } & 0.036 & 0.679(0.472-0.976) \\ \text { LINC00460 } & <0.001 & 1.318(1.151-1.509) \\ \text { riskScore } & <0.001 & 1.681(1.488-1.897)\end{array}$

\section{c TCGA $(n=477)$ ROC curve $($ AUC $=0.743)$}

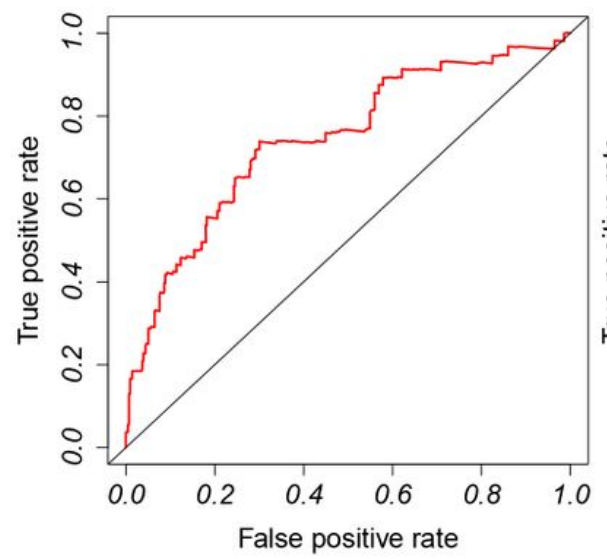

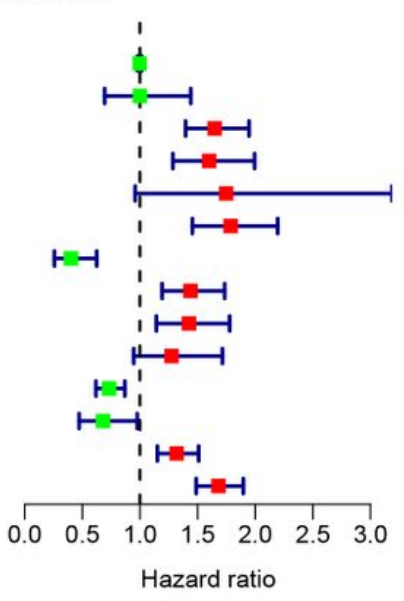
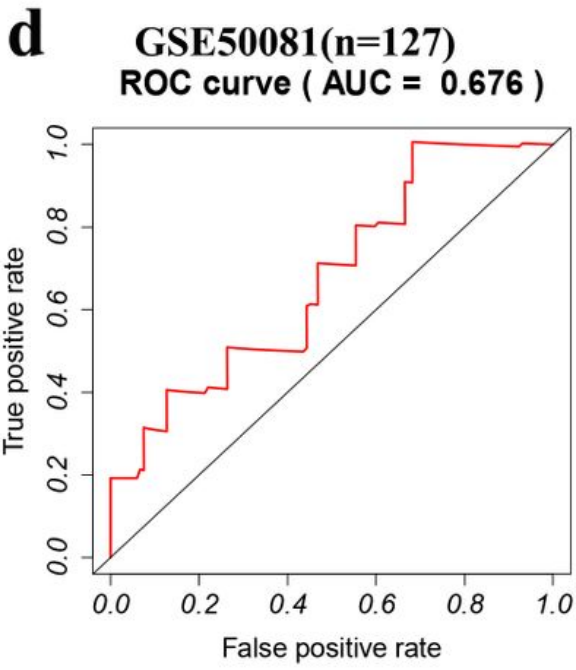

multivariable Cox

$\begin{array}{rrr} & \text { pvalue } & \text { Hazard ratio } \\ \text { age } & 0.834 & 1.002(0.982-1.023)\end{array}$

gender $\quad 0.388 \quad 0.840(0.566-1.247)$

stage $\quad 0.052 \quad 1.644(0.996-2.713)$

T $\quad 0.322 \quad 1.135(0.883-1.457)$

M $\quad 0.537 \quad 0.669(0.187-2.399)$

$\begin{array}{lll}\mathrm{N} & 0.607 & 1.121(0.726-1.729)\end{array}$

LINC00324 $0.274 \quad 0.763(0.469-1.239)$

LINC01116 $0.069 \quad 0.756(0.559-1.022)$

$\begin{array}{lll}\text { CASC15 } & 0.570 & 1.094(0.802-1.492)\end{array}$

LINC00857 $0.011 \quad 0.621(0.430-0.898)$

CRNDE $\quad 0.710 \quad 0.963(0.788-1.176)$

'GAS6-AS1' $0.758 \quad 0.945(0.658-1.357)$

LINC00460 $0.264 \quad 1.092(0.936-1.273)$

riskScore $<0.001 \quad 1.785(1.340-2.377)$

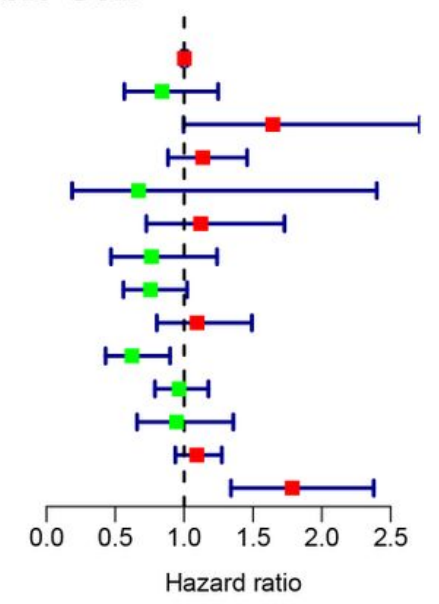

e GSE31210 $(n=226)$ ROC curve $($ AUC $=0.842)$

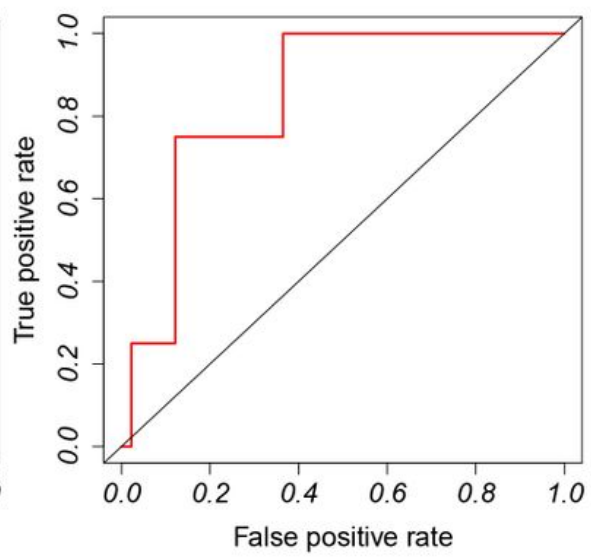

Figure 4

Validation of the potency of the seven IncRNAs signature. Univariable (a) and multivariable (b) cox regression of the clinical features, seven IncRNAs and riskscore. The time-dependent ROC analysis from the TCGA(c), GSE50081(d) and GSE31210(e) groups. 


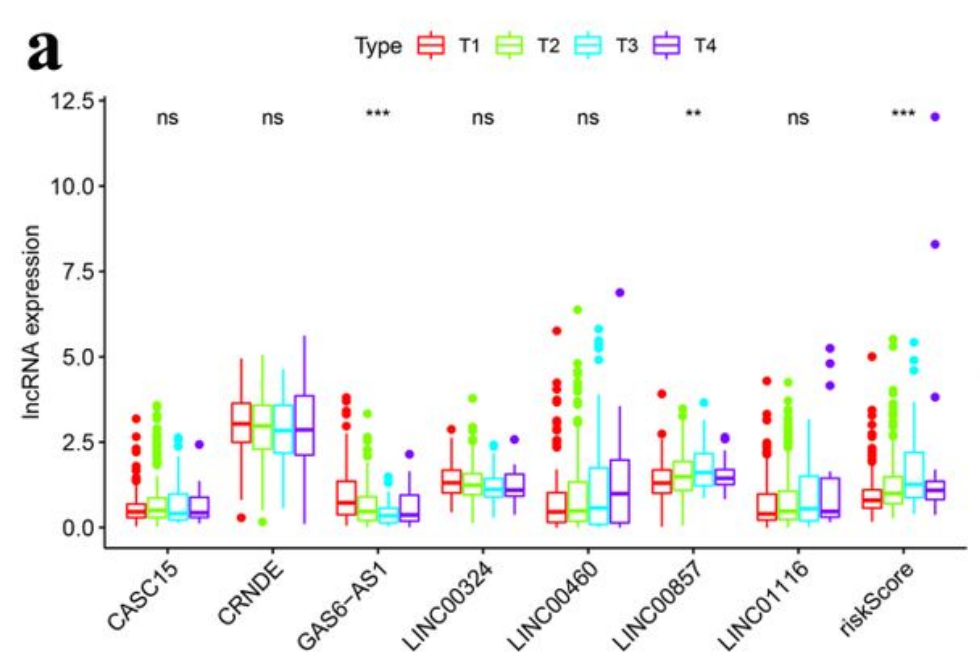

b

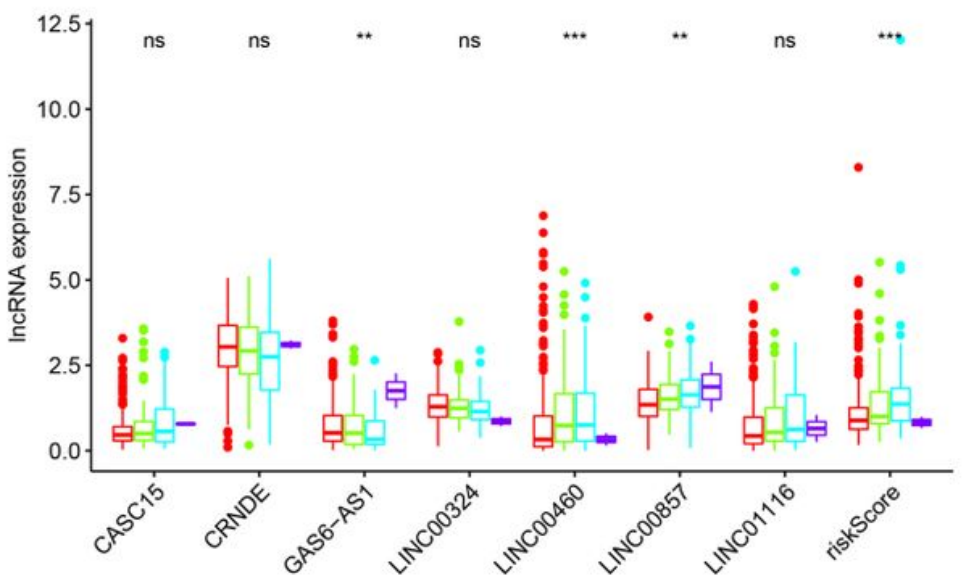

c

Type 追 $\mathrm{mo}$ 穴 $\mathrm{M}$

d
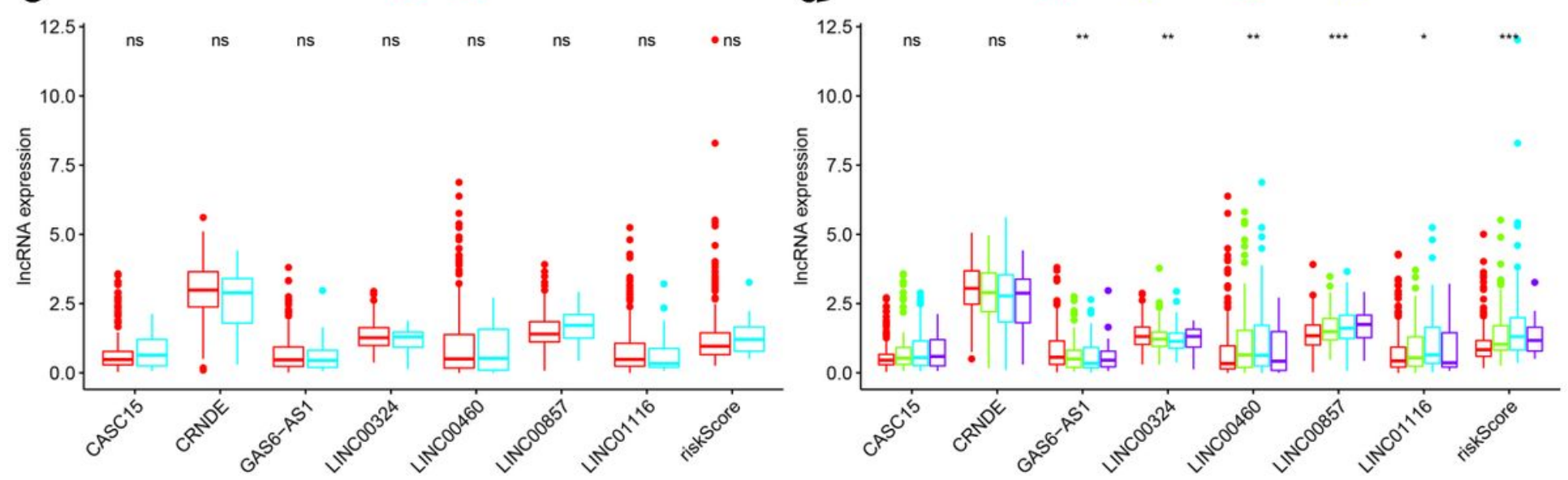

Figure 5

the relationship between clinical features and the seven IncRNAs signature. Box plots of correlation of the seven IncRNAs and signature with T (a), N (b), M (c) and stage (d). 
$\mathbf{a}$

Subtype 追 low 官 high

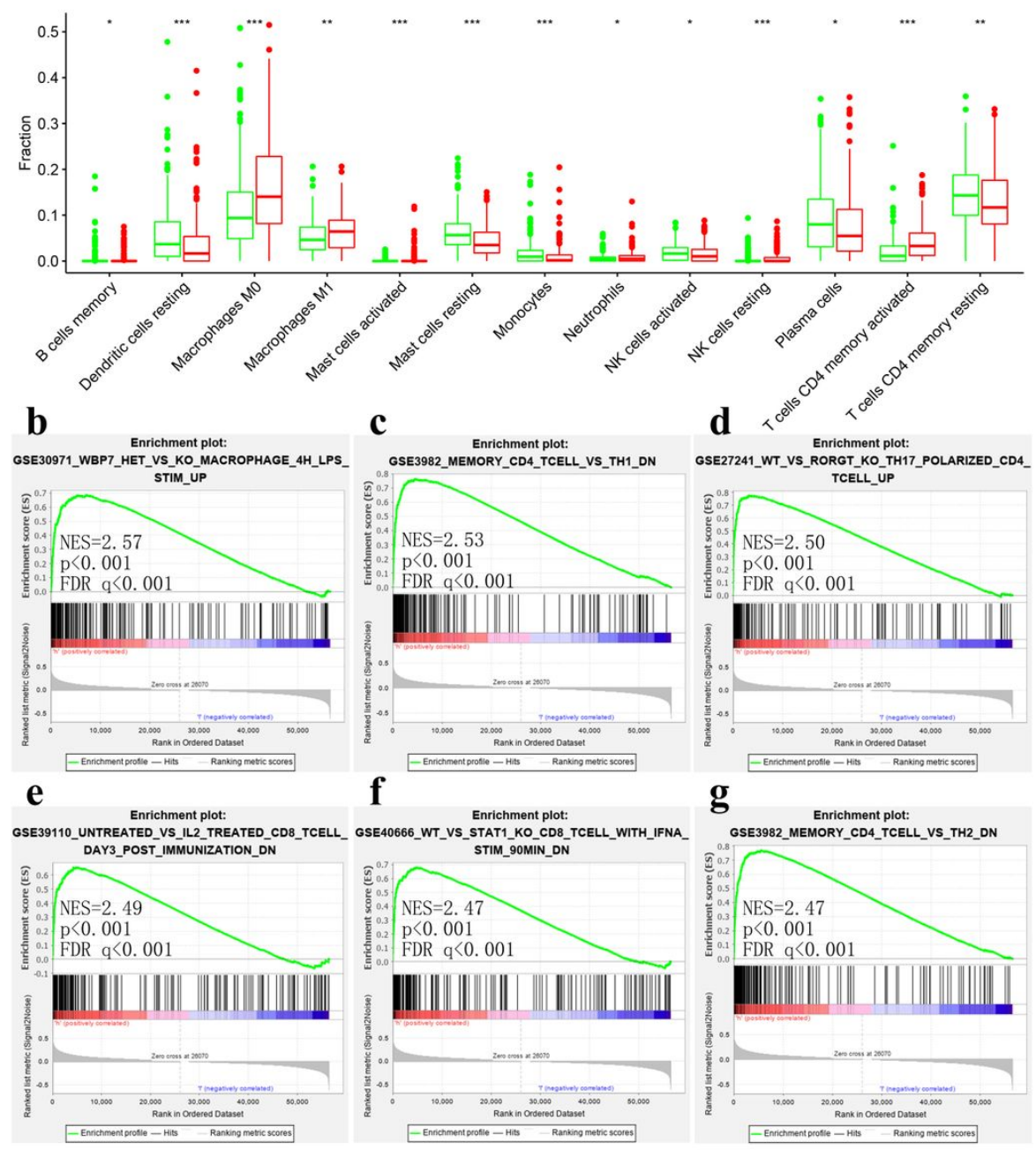

\section{Figure 6}

The significantly infiltrated TIICs and immune pathways within two risk groupsof LUAD. Differently infiltrated TIICsof the two risk groups in the Cibersortx analysis(a).Top six enriched plots from GSEA analysis(b-g). Abbreviations: GSEA, gene set enrichment analysis; ES, enrichment score; NES, normalized ES; $p$, normalized p-value. 